\title{
Antimicrobial Activity of Coleus For skohlii (Wild) Briq and Costus Igneus N.E.Br.
}

\author{
Kala, S. \\ Department of Botany, Seethalakshmi Ramaswami College, Trichirappalli, India.
}

\begin{abstract}
Medicinal plants are the wealthy source of antibacterial agents and curatives. The use of plants in treatment of burns, dermatophytes and infectious diseases is common in traditional medicine. The development of new antimicrobial agents against resistant pathogens is increasing interest. It was found that most plant extracts studied had antibacterial and antifungal activities. In the present investigation, the effect of different extracts namely petroleum ether, methanol, ethyl acetate, acetone and chloroform were tested on Gram positive bacteria like Bacillus subtilis, Staphylococcus aureus and Gram negative bacteria E coli, Pseudomonas aeruginosa and the yeast Candida utilis by disc diffusion and agar well diffusion method. All the extracts showed significant activity against all pathogens, but the methanolic extract showed maximum zone of inhibition against all the microorganisms. Both the gram positive bacteria tested are found to be more sensitive compared to gram negative bacteria which recorded minimum inhibition zone. The plant extracts were found to be more inhibitory towards fungus tested. This study scientifically supports the usage of whole plant as a remedy for various superficial bacterial and fungal infections in traditional medicine.
\end{abstract}

Key words: antimicrobial agents, methanol, gram positive bacteria, gram negative bacteria

\section{Introduction}

Infectious diseases are the world's leading cause of premature deaths, killing almost 50,000 people every day. Infections due to variety of bacterial etiologic agents such as pathogenic Escherichia coli, Salmonella spp., Staphylococcus aureus are most common. In recent years drug resistance to human pathogenic bacteria has been commonly reported from all over the world (Piddock KJV, Wise R, 1989; Singh et al., 1992; Mulligen et al., 1993) Due to the indiscriminate application of antibacterial drugs most of the microbial organisms have developed high resistance to a good number of the commercial antibiotics. This coupled with other problems like the dangerous side effects of some commercial antibiotic drugs have led the scientists to think of other alternatives. There is a need to develop alternative antimicrobial drugs for the treatment of infectious diseases; one approach is to screen local medicinal plants for possible antimicrobial properties. Medicinal plants are the nature's gift to human being to make disease free healthy life. Herbal medicine is still the mainstay of about 75 $80 \%$ of the whole population, mainly in developing countries, for primary health care because, better compatibility with the human body and fewer side effects (Barmet, 1992). The objective of the present research was to authenticate the antibacterial activity of the various extracts namely petroleum ether, methanol, ethyl acetate, acetone and chloroform obtained from various parts of Coleus forskohlii (wild) Briq and Costus igneus N.E.Br.

\section{Coleus forskohlii(wild):}

Coleus forskohlii (wild) Briq [Syn. C. barbatus (Andr.) Benth.] is a plant of Indian origin (Valdes et al. 1987) and belongs to the family Lamiaceae (previously Labiatae). It is the most important species of genus Coleus popularly known as Mainamool or Manganiberu or Makandi beru in Karnataka and garmar in Maharashtra. It is distributed in sub-tropical Himalayas from Gharwal to Nepal up to an altitude of $2500 \mathrm{~m}$ above mean sea level including Pakistan and Sri Lanka. Traditionally, the roots have been used for preparation as condiments in pickles and preparation of pickles (Anon., 1950) and also for medicinal purposes by the Ayurvedic schools of medicines (Ammon and Muller, 1985). Root juice is given to children suffering from constipation (Singh et al., 1980). In India the crop is cultivated in the parts of Gujarat, Maharashtra, Rajasthan, Karnataka and Tamil Nadu and is being grown in an area of more than 2500 hectares for its tuberous roots.

\section{Costus igneus N.E.Br.:}

Costus igneus, common name Fiery Costus or Spiral Flag, is a species of herbaceous plant in the Costaceae family. The plant grows very quickly and the propagation is by stem cutting. It needs sunshine but it also grows in slightly shady areas. This plant has large fleshy looking leaves. The undersides of these large, smooth, dark green leaves have light purple shade. The leaves are spirally arranged around the stem, forming attractive, arching clumps arising from underground rootstocks. The maximum height of these plants is about two feet. The flowers are orange in color and are beautiful, 1.5-inch diameter. Flowering occurs during the 
warm months and they appear to be cone-like heads at the tips of branches. The whole plant $\mathrm{C}$. igneus were used for it anti-diabetic property and prevents the body from disease, protects mind and which prolongs the longevity of life. It is also possible to consume the leaves by drying and grinding powder of the leaves. The rhizome has been used to treat fever, rash, asthma, bronchitis, intestinal worms, ailments of eyes, stomach, neck, jaws, tongue, mouth and also be used for curing fever, edema, wheezing (dyspnoea), haemorrhoids, spermaturia. In siddha medicine system C. igneus root has been used as in the form of powder (chooranam), decoction (kudineer) and oil (thylam).

\section{Materials and method}

Collection of plant: The Leaves, roots and stem of the Coleus forskholii and Costus igneus were collected in the month of April 2012 from the Diamond Jubilee Herbal Garden, Seethalakshmi Ramaswami College, Trichirappalli, Tamil Nadu. They were washed thoroughly with running tap water followed by rinsing with distilled water and then the different parts were separated and cut into small pieces. They were shade dried at room temperature then pulverized into powder. Powdered samples were stored in an air tight container till further use.

Authentication of Plant: The plant material was identified and authenticated in Rapinat Herbarium, St.Joseph's College, Trichirappalli.

Preparation of extracts: The dried powder of sample was successively extracted with petroleum ether, acetone, chloroform, methanol and ethyl acetate in soxhlet apparatus. The extract was stored at $4{ }^{\circ} \mathrm{C}$ and used for antibacterial activity.

Test Organisms: Gram positive \& Gram negative bacteria and fungus were used as test organism for this study. Gram positive bacteria such as Bacillus subtilis, Staphylococcus aureus, Gram negative bacteria such as Escherichia coli and Pseudomonas aeruginosa and fungus Candida utilis. The organisms were sub cultured on to nutrient agar in order to determine their viability.

\subsection{Antibacterial activity \\ 2.1.1. Disc diffusion method Principle}

Disc diffusion method provides a simple and reliable test in routine clinical bacteriology in order to find out the effect of a particular substance on a specific bacterium. This method consists of impregnating small circular discs of standard filter paper with given amount of a chosen concentration of substance. The discs are placed on plates of culture medium previously spread with a bacterial inoculum to be tested. After incubation the degree of sensitivity is determined by measuring the inhibition zone produced by the diffusion of the antibiotic substances from the discs into the surrounding medium.

\section{Procedure}

Circular discs of $6 \mathrm{~mm}$ diameter were prepared from Whatman No.1 filter paper and sterilized in an autoclave. Each paper disc was impregnated with $0.2 \mathrm{~mL}$ of test compound (leaf extract) in the respective solvent for overnight and placed on nutrient agar plates seeded with the test bacterium. The plates were incubated at $37^{\circ} \mathrm{C}$ for $24 \mathrm{~h}$. After $24 \mathrm{~h}$ the zone of inhibition around each disc was measured and recorded. Each extract was tested in triplicate to ensure the reliability of the result. Chloramphenicol $(30 \mathrm{~g} / \mathrm{disc})$ was used as the reference (positive control). A negative control was prepared with only the solvent used for extraction (Rosoanaivo and Ratsimamanga-Urverge, 1993).

\subsubsection{Agar well diffusion method}

It is also known as plate hole diffusion method or cup diffusion method (Kudi et al., 1999). Principle

It is an important method for studying the inhibitory effect of any compound (plant extract or antibiotics) on the growth and multiplication of a particular bacterium.

\section{Procedure}

Nutrient agar was used as the culture medium for this assay. The molten agar was dispensed in presterilized Petri dishes $(25 \mathrm{ml}$ each) and allowed to cool. These agar plates were homogenously inoculated with the test bacterium previously suspended in tryptose broth $(106 \mathrm{cells} / \mathrm{mL})$. The plates were allowed to solidify. After solidification, holes/wells of $6 \mathrm{~mm}$ diameter were punched into the agar with the help of flamed cork borer. $0.2 \mathrm{ml}$ of the plant extract was filled in each hole. The Petri dishes were incubated at $37^{\circ} \mathrm{C}$ for $24 \mathrm{~h}$. After this incubation period, the diameter of the inhibition zone formed around each hole was measured and recorded. Testing was carried out for each bacterium in triplicate. Negative control was prepared using respective solvents used for extraction. Hundred microlitres of Chloramphenicol ( $300 \mathrm{~g} /$ well) was used as positive control. 


\subsection{Antifungal assays}

Antifungal activity of the plant extract was determined by the following assays.

\subsubsection{Paper disc agar diffusion method Principle}

The antimycotic activity of the plant extracts were evaluated by paper disc agar diffusion method. This method consists of impregnating small circular discs of standard filter paper with given amount of a chosen concentration of substance. The discs were placed on plates of culture medium previously spread with the fungal spores (inoculum). After incubation, the degree of sensitivity was determined by measuring the inhibition zone produced by diffusion of the antibiotic substance from the disc into the surrounding medium.

\section{Procedure}

Test plates were prepared with Sabouraud Dextrose agar medium and inoculated on the surface with a spore suspension of $106 \mathrm{CFU} / \mathrm{mL}$. Sterile paper discs (Whatman No.1) of $6 \mathrm{~mm}$ diameter impregnated with the extract were placed over the test plates. Nystatin (Sigma) $30 \mathrm{~g} /$ disc was used as standard. The plates were incubated at $30{ }^{\circ} \mathrm{C}$ for $48 \mathrm{~h}$. The diameter of growth inhibition zone around each disc was measured after $48 \mathrm{~h}$ (Barry and Thornsberry, 1991).

\subsubsection{Agar well diffusion method Principle}

The antifungal activity of the plant extract to various fungi was evaluated by agar well diffusion method. The diameter of the inhibition zone is an indicator of the antifungal activity.

\section{Procedure}

Potato dextrose agar was used to culture the fungal organism. The plates were inoculated with $24 \mathrm{~h}$ culture of respective fungi. With the help of a flamed cork borer $6 \mathrm{~mm}$ wells were cut and to each of the well 0.1 $\mathrm{mL}$ of the extract were aseptically added with the help of sterile syringe. The plates were incubated at room temperature. Inhibition was recorded by measuring the diameter of the inhibition zone after $72 \mathrm{~h}$. Nystatin (300 $\mathrm{g} /$ well) was used as standard for comparison of antifungal activity (Gobdi and Irobi, 1992).

\section{Results}

Plant derived medicines have made significant contribution towards treatment of diseases as is done in cases of Unani and Ayurvedic system of medicines. The presence of antifungal and antimicrobial substances in the higher plants is well established as they have provided a source of inspiration for novel drug compound. In the present study the antibacterial and antifungal investigations have been done for Coleus forskohlii (wild) Briq and Costus igneus N.E.Br. using different solvents like petroleum ether, methanol, chloroform, acetone and ethyl acetate against Bacillus subtilis, Staphylococcus aureus,, Escherichia coli, Pseudomonas aeruginosa and Candida utilis. Different extracts have potent antimicrobial activity against Gram positive, Gram negative bacteria and fungus indicating the presence of broad spectrum antimicrobial substance in the plants. The antimicrobial activity was determined by measuring the diameter of zone of inhibition recorded. The results revealed variability in inhibitory concentrations of each extract against a given bacteria. In general, methanol extracts of the selected plants appeared to be effective source of active antimicrobial agents.

Table - 1 Antimicrobial activity of Coleus forskohlii (wild) Briq Disc diffusion method

\begin{tabular}{|c|c|c|c|c|c|c|}
\hline \multirow[t]{2}{*}{ Solvents } & \multirow[t]{2}{*}{ Part } & B.s & S.a & E.c & P.a & C.u \\
\hline & & \multicolumn{5}{|c|}{ Inhibition zone (in mm) } \\
\hline \multirow{3}{*}{ P.E } & $\mathbf{L}$ & 13 & 11 & 9 & 7 & 11 \\
\hline & $\mathbf{S}$ & 11 & 9 & 7 & 7 & 10 \\
\hline & $\mathbf{R}$ & 15 & 11 & 9 & 8 & 13 \\
\hline \multirow{3}{*}{$\mathbf{M}$} & $\mathbf{L}$ & 15 & 13 & 11 & 8 & 13 \\
\hline & $\mathbf{S}$ & 13 & 11 & 9 & 7 & 11 \\
\hline & $\mathbf{R}$ & 18 & 14 & 13 & 10 & 15 \\
\hline \multirow{3}{*}{ E.A } & $\mathbf{L}$ & 11 & 9 & 7 & 7 & 9 \\
\hline & $\mathbf{S}$ & 9 & 9 & 6 & - & 9 \\
\hline & $\mathbf{R}$ & 12 & 11 & 8 & 7 & 11 \\
\hline \multirow{3}{*}{$\mathbf{A}$} & $\mathbf{L}$ & 9 & 7 & 6 & 6 & 8 \\
\hline & $\mathbf{S}$ & 7 & - & 6 & - & 7 \\
\hline & $\mathbf{R}$ & 8 & 9 & 7 & 7 & 10 \\
\hline \multirow{3}{*}{ C } & $\mathbf{L}$ & 9 & 9 & 9 & 7 & 10 \\
\hline & $\mathbf{S}$ & 11 & 7 & 7 & 7 & 9 \\
\hline & $\mathbf{R}$ & 11 & 10 & 10 & 8 & 13 \\
\hline
\end{tabular}


Note: P.E- Petroleum ether; M- Methanol; E.A- Ethyl Acetate; A- Acetone; C-chloroform.

B.s- Bacillus subtilis, S.a-Staphylococcus aureus, E.c-Escherichia coli; P.a- Pseudomonas aeruginosa; C.aCandida utilis.

L-leaf; S-Stem; R-Root

The results of antimicrobial activity of Coleus forskohlii (wild) Briq by disc diffusion method is given in Table1. When the solvents were considered, methanol showed the maximum inhibition. Among the organisms, Bacillus subtilis was found to be more sensitive gram positive bacteria showing more inhibition. Of the gram negative bacteria Escherichia coli was comparatively more sensitive to the extracts and inhibition was more in methanol. The growth of fungus was inhibited more than gram negative bacteria and inhibition is more in methanol extract. The root of C. forskohlii (wild) Briq compared to leaf and stem, showed maximum inhibition towards all microorganisms and in all the extracts. The result of agar well diffusion method is given in Table- 2; the same observation was recorded but with little difference in the inhibition zone which might be due the diffusion of extract.

Table - 2 Antimicrobial activity of Coleus forskohlii (wild) Briq Agar well diffusion method

\begin{tabular}{|c|c|c|c|c|c|c|}
\hline \multirow[t]{2}{*}{ Solvents } & \multirow[t]{2}{*}{ Part } & B.s & S.a & E.c & P.a & C.u \\
\hline & & \multicolumn{5}{|c|}{ Inhibition zone (in mm) } \\
\hline \multirow{3}{*}{ P.E } & $\mathbf{L}$ & 11 & 9 & 9 & 6 & 10 \\
\hline & $\mathbf{S}$ & 10 & 9 & 6 & 6 & 11 \\
\hline & $\mathbf{R}$ & 14 & 10 & 9 & 8 & 11 \\
\hline \multirow{3}{*}{$\mathbf{M}$} & $\mathbf{L}$ & 14 & 12 & 10 & 7 & 12 \\
\hline & $\mathbf{S}$ & 11 & 12 & 9 & 7 & 11 \\
\hline & $\mathbf{R}$ & 17 & 13 & 11 & 11 & 16 \\
\hline \multirow{3}{*}{ E.A } & $\mathbf{L}$ & 9 & 9 & 8 & 8 & 70 \\
\hline & $\mathbf{S}$ & 11 & 8 & 7 & 6 & 9 \\
\hline & $\mathbf{R}$ & 11 & 11 & 9 & 9 & 12 \\
\hline \multirow{3}{*}{$\mathbf{A}$} & $\mathbf{L}$ & 10 & 9 & 6 & 7 & 9 \\
\hline & $\mathbf{S}$ & 8 & 6 & 7 & 6 & 9 \\
\hline & $\mathbf{R}$ & \begin{tabular}{|l|}
11 \\
\end{tabular} & 9 & 8 & 8 & 12 \\
\hline \multirow{3}{*}{ C } & $\mathbf{L}$ & \begin{tabular}{|l|}
10 \\
\end{tabular} & 8 & 8 & - & 10 \\
\hline & $\mathbf{S}$ & \begin{tabular}{|l|}
12 \\
\end{tabular} & 8 & 8 & 8 & 9 \\
\hline & $\mathbf{R}$ & 12 & 11 & 11 & 7 & 12 \\
\hline
\end{tabular}

Note: P.E- Petroleum ether; M- Methanol; E.A- Ethyl Acetate; A- Acetone; C-chloroform.

B.s- Bacillus subtilis, S.a-Staphylococcus aureus, E.c-Escherichia coli; P.a- Pseudomonas aeruginosa; C.aCandida utilis.

L-leaf; S-Stem; R-Root

The results of antimicrobial activity of Costus igneus N.E.Br by disc diffusion method is given in Table- 3 and by agar well diffusion method in Table-4. As in the case of Coleus forskohlii, maximum inhibition was observed in methanol extract, while the root is found to have bioactive compounds more. Both the gram positive bacteria tested are found to be more sensitive compared to gram negative bacteria which recorded minimum inhibition zone. The plant extracts were found to be more inhibitory towards fungus tested. There was not much difference between the inhibitory zone recorded in disc diffusion and agar well diffusion method.

Table - 3 Antimicrobial activity of Costus igneus N.E.Br. Disc diffusion method

\begin{tabular}{|c|c|c|c|c|c|c|}
\hline \multirow[t]{2}{*}{ Solvents } & \multirow[t]{2}{*}{ Part } & B.s & S.a & E.c & P.a & C.u \\
\hline & & \multicolumn{5}{|c|}{ Inhibition zone (in mm) } \\
\hline \multirow{3}{*}{ P.E } & $\mathbf{L}$ & 17 & 16 & 11 & 10 & 12 \\
\hline & $\mathbf{S}$ & 11 & 13 & 9 & 9 & 10 \\
\hline & $\mathbf{R}$ & 9 & 10 & 7 & 8 & 9 \\
\hline \multirow{3}{*}{$\mathbf{M}$} & $\mathbf{L}$ & 19 & 17 & 11 & 11 & 13 \\
\hline & $\mathbf{S}$ & 15 & 14 & 9 & 11 & 12 \\
\hline & $\mathbf{R}$ & 11 & 11 & 9 & 9 & 11 \\
\hline \multirow{3}{*}{ E.A } & $\mathbf{L}$ & 13 & 11 & 11 & 9 & 12 \\
\hline & $\mathbf{S}$ & 10 & 9 & 8 & 7 & 9 \\
\hline & $\mathbf{R}$ & 9 & 9 & 7 & - & 8 \\
\hline \multirow{3}{*}{$\mathbf{A}$} & $\mathbf{L}$ & 11 & 10 & 10 & 9 & 12 \\
\hline & $\mathbf{S}$ & 9 & 9 & - & 7 & 9 \\
\hline & $\mathbf{R}$ & 8 & 7 & - & 7 & 8 \\
\hline \multirow{3}{*}{$\mathbf{C}$} & $\mathbf{L}$ & 11 & 9 & 9 & 8 & 12 \\
\hline & $\mathbf{S}$ & 8 & 7 & 7 & - & 11 \\
\hline & $\mathbf{R}$ & 8 & 6 & - & - & 9 \\
\hline
\end{tabular}

Note: P.E- Petroleum ether; M- Methanol; E.A- Ethyl Acetate; A- Acetone; C-chloroform. 
B.s- Bacillus subtilis, S.a-Staphylococcus aureus, E.c-Escherichia coli; P.a- Pseudomonas aeruginosa; C.aCandida utilis.

L-leaf; S-Stem; R-Root

Table - 4 Antimicrobial activity of Costus igneus N.E.Br.Agar well diffusion method

\begin{tabular}{|c|c|c|c|c|c|c|}
\hline \multirow[t]{2}{*}{ Solvents } & \multirow[t]{2}{*}{ Part } & B.s & S.a & E.c & P.a & C.u \\
\hline & & \multicolumn{5}{|c|}{ Inhibition zone (in mm) } \\
\hline \multirow{3}{*}{ P.E } & $\mathbf{L}$ & 16 & 16 & 12 & 11 & 11 \\
\hline & $\mathbf{S}$ & 12 & 14 & 9 & 10 & 11 \\
\hline & $\mathbf{R}$ & 10 & 10 & 8 & 8 & 9 \\
\hline \multirow{3}{*}{ M } & $\mathbf{L}$ & 17 & 16 & 12 & 10 & 12 \\
\hline & $\mathbf{S}$ & 19 & 11 & 10 & 9 & 12 \\
\hline & $\mathbf{R}$ & 11 & 9 & 9 & 8 & 11 \\
\hline \multirow{3}{*}{ E.A } & $\mathbf{L}$ & 15 & 13 & 12 & 10 & 14 \\
\hline & $\mathbf{S}$ & 11 & 10 & 9 & 8 & 11 \\
\hline & $\mathbf{R}$ & 9 & 8 & 8 & 6 & 9 \\
\hline \multirow{3}{*}{$\mathbf{A}$} & $\mathbf{L}$ & 9 & 12 & 11 & 10 & 10 \\
\hline & $\mathbf{S}$ & 7 & 10 & 7 & 8 & 10 \\
\hline & $\mathbf{R}$ & 8 & 8 & 8 & 6 & 7 \\
\hline \multirow{3}{*}{ C } & $\mathbf{L}$ & 10 & 11 & 10 & 9 & 11 \\
\hline & $\mathbf{S}$ & 9 & 8 & 9 & 7 & 12 \\
\hline & $\mathbf{R}$ & 8 & 8 & 6 & - & 11 \\
\hline
\end{tabular}

Note: P.E- Petroleum ether; M- Methanol; E.A- Ethyl Acetate; A- Acetone; C-chloroform.

B.s- Bacillus subtilis, S.a-Staphylococcus aureus, E.c-Escherichia coli; P.a- Pseudomonas aeruginosa; C.aCandida utilis.

L-leaf; S-Stem; R-Root

\section{Discussion}

In this study the antimicrobial activity has been demonstrated against various strains which include gram positive, gram negative bacteria and fungi, because of the great medicinal relevance of the selected plants with the recent years. The presence of antimicrobial substances in higher plants is well established as they provided a source of inspiration for novel drug compounds as plants derived medicines have made significant contribution towards human health. Plant based antimicrobials have enormous therapeutic potential as they can serve the purpose without any side effects that are often associated with synthetic antimicrobial compounds. In the present study, methanol extracts appeared to be effective source of active antimicrobial agents. Methanol was found to bestowed with antimicrobial agents showing maximum inhibition. Eloff (1998) also reported that methanol was the most effective solvent for plant extraction than ethanol, n-hexane and water. Cowan(1999) mentioned that most of the antibiotic compounds already identified in plants are reportedly aromatic or saturated organic molecules which can easily solubilized in organic solvents. Similar results showing that the alcoholic extract having the best antimicrobial activity is also reported by Preethi(2010) in Leucas aspera, Holarrhena antidysenterica. Seyydnejad(2010) also studied the effect of different alcoholic viz. ethanol and methanol for antimicrobial activity and observed that this difference in the activity between different alcoholic extract is due to the difference between extract compounds in this two extract. Gram negative bacteria recorded minimum inhibition zone. Various workers have already shown that Gram positive bacteria are more susceptible towards plants extracts as compared to Gram negative bacteria (Lin et al., 1999; Parekh and Chanda, 2006). These differences may be attributed to fact that the cell wall in Gram positive bacteria is of a single layer, whereas the Gram negative cell wall is multilayered structure (Yao et al., 1995). Alternatively, the passage of the active compound through the Gram negative cell wall may be inhibited. It is thought that observed differences may result from the doses used in this study. The reason for the different sensitivity between Gram-positive and negative bacteria could be ascribed to the morphological differences between these micro-organisms, Gramnegative bacteria having an outer phospholipidic membrane carrying the structural lipopolysaccharide components. This makes the cell wall impermeable to lipophilic solutes, while porins constitute a selective barrier to the hydrophilic solutes with an exclusion limit of about $600 \mathrm{Da}$ (Nikaido and Vaara 1985). The Grampositive bacteria should be more susceptible having only an outer peptidoglycan layer which is not an effective permeability barrier ( Scherrer and Gerhardt 1971). In addition, microorganisms show variable sensitivity to chemical substances related to different resistance levels between strains (Cetin and Gurler, 1989).

\section{Conclusion}

The selected plants contain potential antimicrobial components that may be of great use for the development of pharmaceutical industries as a therapy against various diseases. The extracts possess significant inhibitory effect against tested pathogens. The above result opens the possibility of finding new clinically 
effective antioxidant drug and could be useful in understanding the relationship between traditional cures and current medicines. Further research is necessary to determine the identity of the antibacterial compounds from within these plants and also to determine their full spectrum of efficacy. This study encourages the cultivation of this highly valuable medicinal plant to meet the increasing demand from traditional medicinal system.

\section{Acknowledgements}

I acknowledge the financial assistance from UGC in the form of a major research project [Project no.40-321/2011(SR)].

\section{References}

[1]. Ammon, HPT and Muller, AB. 1985 "Forskolin: from an ayurvedic remedy to a modern agent", Planta Med., 46, 473-477.

[2]. Anonymous. 1950 "Coleus forskohlii. In: Wealth of India-Raw materials, Vol. II. Central Scientific and Industrial Research, New Delhi, 308.

[3]. Barmet, H. 1992 The natural pharmacy: An encyclopedic illustrated guide to medicine from nature. Mirriampolunin and Christopher Robins, Great Britain.

[4]. Barry, A. and Thornsberry, C. 1991 Susceptibility test and diffusion test procedures. In: Manual of clinical microbiology. Balows, A. and Shadomy, H. J. (eds.). American Society of Microbiology, Washington DC.pp. 1526-1542.

[5]. Cetin, T.E., Gurler, N 1989 Bakterilerin antibiyotiklere duyaarlilik deneyinin yapilmasi. Kukem Dergisi, 12: 2-5.

[6]. Cowan M 1999 Plant products as antimicrobial agents. Clin. Microbiol. Rev.; 12: 564-582.

[7]. Eloff JN 1998 Which extract should be used for the screening and isolation of antimicrobial components from plants? J. Ethnopharmacol. 60: 1-8.

[8]. Gobdi, T. A. and Irobi, O. N. 1992 Antibacterial activities of crude extracts of Aspergillus

[9]. quadrilineatus isolated from Nigerian cereal. African Journal of Pharmacy and Pharmaceutical Sciences22, 101-106.

[10]. Kudi, A. C., Umoh, J. U., Eduvie, L. O. and Gefu, J. 1999 Screening of some Nigerian Medicinal Plants from antibacterial activity. Journal of Ethnopharmacology 67, 225-228

[11]. Lin, J., Opoku, A.R., Geheeb-Keller, M., Hutchings,A.D., Terblanche, S.E., Jager, A.K., van Staden, J 1999 Preliminary screening of some traditional zulu medicinal plants for anti-inflammatory and antimicrobial activities. J Ethnopharmacol. 68: 267274 .

[12]. Nikaido, H. \& Vaara, M 1985 Molecular basis of bacterial outer membrane permeability. Microbiological Reviews 1, 1 32.Parekh, J., Chanda, S 2006 In vitro antimicrobial activities of extract of Launaea procumbens Roxb.(Labiateae), Vitis vinifera (Vitaceae) and Cyperus rotundus (Cyperaceae). Afr. J. Biomed. Res. 9: 89-93.

[13]. Piddock KJV, Wise R 1989 J.Antimicrobial chemotherapy, 23:475-83

[14]. Preethi R, Devanathan V V, Loganathan M 2010Antimicrobial and Antioxidant Efficacy of Some Medicinal Plants Against Food Borne Pathogens. Adv. in Bio.Res.. 4 (2): 122-125.

[15]. Rosoanaivo, P. and Ratsimamanga-Urverge, S. 1993 Biological evaluation in plants with reference to Mal. J. Microbiol. Vol 6(2) 2010, pp. 140-148 Malagasy flora. Monograph of the IFS - NAPRECA Workshop on Bioassays. Antananarivo Madagascar, Madagascar, pp. 72-79.

[16]. Scherrer, R. \& Gerhardt, P. 1971 Molecular sieving by the Bacillus megaterium cell wall and protoplast. Journal of Bacteriology 107,718735 .

[17]. Seyydnejad SM, Niknejad M, Darabpoor I, Motamedi H 2010 Antibacterial Activity of Hydroalcoholic Extract of Callistemon citrinus and Albizia lebbeck. American J.of App. Sci. 7 (1): 13-16.

[18]. Singh, S and Tandon, JS 1980 "Coleonal and forskolin from Coleus forskohlii", Planta Med., 45, 62-63.

[19]. Singh M, Chaudhry MA, Yadava JNS, Sanyal SC,1992 J Antimicrobial Chemotherapy, 29:159-68.

[20]. Mulligen ME, Kauffman CA. Yu VL1993 American Journal of medicine, 94:313-28.

[21]. Valdes, LJ; Mislankar, SG and Paul, AG. 1987 "Coleus barbatus (C. forskohlii) (Lamiaceae) and the potential new drug forskohlin (Coleonol)", Econ. Bot., 44,474-483.

[22]. Yao, J., Moellering, R 1995 Antibacterial agents. In: Manual of Clinical Microbiology, Murray P, Baron E, Pfaller M, Tenover F, Yolken R (Eds), ASM, Washington DC, pp.1281-1290. 